\title{
Comandando desde las Alturas: el PAPEL DE la Fuerza Aérea Colombiana en la OPERaCión ANORí (1973)
}

\author{
Anny Durley Valbuena Gómez ${ }^{1}$ \\ RODRIGO MEZÚ MINA ${ }^{2}$ \\ ANDRÉS RAMÍREZ BERNAL ${ }^{3}$
}

\section{RESUMEN}

La Operación Anorí se llevó a cabo entre el 7 de agosto y el 18 octubre de 1973, en el municipio de Anorí, Antioquia. En ella participaron de manera conjunta el Ejército Nacional, la Fuerza Aérea Colombiana-FACy la Armada Nacional, con el objetivo de neutralizar a los integrantes del Ejército de Liberación Nacional- ELN- ubicados en el territorio. Este artículo indaga sobre el papel de la Fuerza Aérea Colombiana en el desarrollo de esta Operación. Para ello se empleó la prensa regional y nacional de la época y bibliografía secundaria. Se lograron establecer dos posturas hegemónicas que existen sobre esta operación. A pesar de la disparidad en las dos posturas, fue posible determinar el consenso con respecto al papel destacado desempeñado por la Fuerza Aérea Colombiana durante la Operación Anorí, mediante el uso de helicópteros UH-1H, equipados para el traslado de tropa, heridos, capturados, muertos y al comandante del C0-10, Coronel Hernán Hurtado Vallejo.

Historiadora de la Universidad Nacional de Colombia. Miembro del grupo Análisis en Contexto y la línea de investigación Deber y Memoria de la Escuela de Postgrados de la FAC.

2 Administrador Aeronáutico de la Escuela Militar de Aviación "Marco Fidel Suárez". Magíster en Estudios Internacionales, aplicado a los Conflictos y la Cooperación de la Universidad Old Dominion, Virginia. Candidato a Doctor y Magíster en Ciencia Política de la Universidad de Los Andes.

3 Historiador de la Universidad Nacional de Colombia. Candidato a magíster en Historia. Integrante de la línea de investigación en Historia Política y Social de la misma Universidad. 
Palabras clave: Operación Anorí, Fuerza Aérea Colombiana-FAC, Ejército de Liberación Nacional-ELN, Estrategias militares, Derechos Humanos.

\section{INTRODUCCIÓN}

La Operación Anorí se realizó en el nordeste antioqueño en 1973 con el fin de neutralizar a una de las principales columnas guerrilleras del ELN. En ella cooperaron de manera conjunta el Ejército, la Fuerza Aérea Colombiana y la Armada Nacional. "Se calcula que 4.000 hombres participaron de la operación que terminó por cercar a Manuel y Antonio Vásquez Castaño, quienes resistieron hasta el último minuto" (CAMARGO, 2017). El presente artículo tiene por objetivo indagar el papel desempeñado por la Fuerza Aérea Colombiana en el desarrollo de esta Operación. Así mismo, la investigación surgió ante la necesidad del país por conocer la historia contemporánea del conflicto y la obligación de la academia por estudiarla de forma analítica.

Este trabajo se desarrolló empleando la historiografía disponible que incluye investigaciones sobre el ELN, publicaciones de integrantes de las Fuerzas Militares interesados en la Operación Anorí. Además, se consultó el periódico regional El Colombiano (Medellín), los diarios de circulación nacional El Tiempo y El Espectador, entre agosto y noviembre de 1973, y la revista Alternativa del pueblo.

El artículo está compuesto por el balance historiográfico de los textos que han abordado esta temática. En primer lugar se presentan los antecedentes y el desarrollo de la Operación Anorí. Más adelante, se indaga sobre la labor de la Fuerza Aérea, en donde se exponen las principales actividades realizadas durante la Operación. Luego, un estudio sobre las denuncias de posibles violaciones de Derechos Humanos $\mathrm{y}$, finalmente, las conclusiones.

\section{BALANCE HISTORIOGRÁFICO}

La producción académica sobre la Operación Anorí no es muy amplia. A continuación, un esbozo de los textos y artículos relacionados con la 
misma. Se destaca el aporte de cada uno de ellos sobre el papel de las Fuerzas Militares, en especial de la Fuerza Aérea Colombiana.

El Libro negro de la represión. Frente Nacional 1958-1974 fue publicado un año después de la Operación Anorí, por la Fundación Comité de Solidaridad con los Presos Políticos. Usando prensa y actas de comités exponen la información más relevante - desde su perspectivafrente a la actividad de las Fuerzas Militares, guerrilleros y otros actores en el conflicto. Su estructura es la de un diario; dividido por años y meses. Para el caso puntual de la Operación aseguran, por ejemplo, que las bajas de soldados fueron mayores a las de miembros del ELN: “...bajas del ejército: 160. Bajas del ELN: 30" (FundaCión COMITÉ DE SOLIDARIDAD CON los Presos Políticos [FCSPP], 1974). Además, se alegan excesos en la implementación de la fuerza militar y denuncias sobre campesinos torturados y exhibidos desde helicópteros sobre el municipio de Anorí (FCSPP, 1974). Lo dicho anteriormente no enuncia la fuente específica para cada caso, dificultando su verificación.

El oficial retirado del Ejército Nacional y sociólogo Gonzalo Bermúdez Rossi (1982) en su texto El poder militar en Colombia: de la colonia a la contemporaneidad expone la posición de las Fuerzas Militares durante los diferentes periodos políticos y sociales en el país. Dedica pocas páginas a la Operación Anorí y no ofrece suficientes datos o información para comprender este suceso, dando lugar a una imagen parcializada. Sin embargo, es relevante su postura frente a la misma, al afirmar que se cometieron excesos de fuerza contra la población que habitaba en el territorio. Para 1973, el autor ya sumaba más de un año de retiro obligatorio de las Fuerzas Armadas, por lo cual no participó en el desarrollo del operativo en el municipio de Anorí.

Olga Behar (1985) publicó el libro Las Guerras de la paz. Dedica un breve apartado a los orígenes del ELN y a la experiencia en Anorí. En 20 páginas recopila dos testimonios opuestos: el de 'Armando Martínez', guerrillero sobreviviente de la operación, y el de un "comandante [anónimo] del Ejército de Colombia". La crónica es amplia en información y anécdotas. Sin embargo, se queda únicamente en el ámbito periodístico. Informa, pero no analiza.

Cóndor en el aire es el único texto dedicado en su totalidad a abordar la Operación Anorí. Escrito por el Coronel de la reserva activa del 
Ejército colombiano Luis Alberto Villamarín Pulido. Se compone por: notas del autor, once capítulos, conclusiones finales, anexos fotográficos y epílogo. Luego de hacer una introducción general sobre el nacimiento y crecimiento del ELN, comenta las operaciones anteriores a Anorí. El libro presenta de forma extensiva las experiencias a lo largo de 1973. Sus principales fuentes son los informes de la operación, el archivo personal del oficial Hernán Hurtado Vallejo y las entrevistas realizadas a los comandantes de este operativo. Es un escrito amplio en detalles, pero no permite entender el proceso general, debido a la ausencia de una estructura clara. Se evidencian, además, problemas de citación lo que dificulta la diferenciación de los documentos empleados, las entrevistas y los puntos de vista del autor.

Carlos Medina Gallego en ELN: una historia de los orígenes aborda, a través de documentos, la perspectiva de esta guerrilla. En el texto se propone que los antecedentes, el surgimiento y la consolidación del ELN van desde 1958 hasta 1966. Medina Gallego sugiere que el auge militar y la mayor influencia de masas se ubican desde 1966 hasta 1973. Carlos Medina trabaja la Operación Anorí en la tercera parte de su libro. Divide en cinco partes este capítulo: Antecedentes de la Operación Anorí; Los operativos militares de Anorí en el contexto de la lucha contrainsurgente latinoamericana; El desarrollo de la Operación Anorí y la dinámica interna de la columna guerrillera de los Vásquez Castaño; Anorí: una lectura desde la oficialidad del Ejército y desde la estructura guerrillera y, finalmente, La asamblea del Anacoreto. Las fuentes para desarrollar este apartado se centran en el archivo histórico del ELN:

Para la argumentación de este fragmento del trabajo hemos tomado en consideración las valoraciones que el ELN hace sobre los operativos de Anorí, consignados en distintos documentos de su memoria histórica. Igualmente, las entrevistas realizadas a Manuel Pérez Martínez y Nicolás Rodríguez Bautista, comandantes político y militar respectivamente. Desde luego que la organización pondera desde su particular apreciación los hechos, magnificando o minimizando los mismos, en el contexto de sus propias representaciones de los acontecimientos y sobre la base del peso que tienen para la construcción de su propia historia (Medina, 2001).

El trabajo realizado por el historiador Medina Gallego tiene el mérito de ser riguroso y las fuentes consultadas son extensas. Sin embargo, para 
los propósitos de este artículo, se queda corto en la medida en que no se ve reflejado el papel en particular de la Fuerza Aérea, ni en general de las Fuerzas Militares. Como ejemplo de lo anterior, encontramos la sección denominada Anorí: una lectura desde la oficialidad del Ejército y desde la estructura guerrillera en donde solamente es citado el texto del Mayor Gonzalo Bermúdez Rossi. Una única fuente es insuficiente para poder afirmar con certeza sobre "los interrogatorios, la tortura física y la ejecución extrajudicial en el más claro desconocimiento de los derechos y garantías de la población civil" (MEDINA, 2001).

Milton Hernández, comandante del ELN, publicó el libro Rojo y negro. Aproximación a la historia del ELN en 1998. Se consultó la segunda edición publicada en el 2004. Dedica el capítulo 27 a la Operación Anorí presentando antecedentes, fechas relevantes, movimientos del Ejército de Liberación Nacional y algunos de las Fuerzas Militares. Con relación al apoyo aéreo, destaca el uso de helicópteros durante los meses de septiembre y octubre en el transporte de tropa, así como en continuos sobrevuelos. En general, el autor relata la reducción de las cuadrillas del ELN hasta el 18 de octubre, con la muerte de los hermanos Vásquez Castaño y 'Lucía'. Sin embargo, no es clara la procedencia de las fuentes de información ni los documentos sobre los detalles de la Operación, las cifras de participantes en los combates, heridos, capturados y muertos, además de alusiones a excesos militares en el trato a la población civil, dificultando con ello corroborar los datos en cuestión.

El libro Hablan los generales (2017). Las grandes batallas del conflicto colombiano contadas por sus protagonistas es una compilación de entrevistas con un apartado dedicado a la Operación Anorí: golpe al corazón del ELN, narración del general retirado Hernán Hurtado Vallejo, militar encargado del Comando Operativo No. 10 en 1973. El texto es el testimonio y posición de las Fuerzas Militares frente a la operación, acompañado de opiniones personales del entonces Teniente Coronel sobre la situación del ELN, los combates, su relación con la población civil en Anorí, los capturados, la estrategia militar y, finalmente, el último cerco a los integrantes de esta guerrilla. Su historia permite comprender la importancia del transporte aéreo mediante los helicópteros, llevando a la tropa y a él mismo por el territorio antioqueño. 
La guerra en los ríos: historia de las unidades fluviales en Infantería de Marina (2016) contiene un capítulo dedicado a la Operación Anorí. Julio César Carranza, su autor, participó como teniente del grupo de Infantería de Marina en el operativo. El libro es un aporte significativo no solo por el testimonio de quien lo escribe, sino por los detalles estructurales frente a la combinación de trabajo entre la Fuerza Aérea, Ejército y Armada. Por ejemplo, Carranza comenta las adversidades sufridas por los cuatro botes que participaron como cerco, transporte y escudo de los helicópteros de la FAC en los afluentes para lograr el movimiento y abastecimiento de la tropa. Igualmente narra cómo ejercieron presión al grupo del ELN hasta la caída de los hermanos Manuel, Antonio y su compañera 'Lucía'. En conclusión, el texto permite conocer las actividades de apoyo del equipo de Infantería de Marina durante la Operación.

Los autores de Fuerzas Militares de Colombia Fjército Nacional Tฯ División (2017): el conflicto armado en las regiones explican los antecedentes y el desarrollo de la Operación Anorí mediante el uso de entrevistas y prensa. La voz del cuerpo del Ejército se comprende bajo el entramado de una Operación nunca antes vista en el país -según sus fuentes-y en la que realizaron a gran escala un "cerco" a los miembros del ELN empleando las tres ramas de las Fuerzas Armadas por aire, tierra y conexiones fluviales. Así, la información en el subcapítulo permite analizar la participación y opinión de los militares en este tipo de operativos, la postura de la prensa local, los movimientos del cuerpo militar y el aporte de la Fuerza Aérea Colombiana -en menor proporción-.

Esta breve reseña ilustra que no se ha estudiado a profundidad la participación de la Fuerza Aérea en la Operación Anorí. Incluso, dentro del tomo 5 dedicado a la FAC del libro La Historia de las Fuerzas Militares, compilado por Álvaro Valencia Tovar (1993), ni siquiera se menciona este acontecimiento.

\section{LA ANTESALA DE LA OPERACIÓN ANORÍ}

Los orígenes del ELN se pueden rastrear desde 1962. Luego de recibir entrenamiento militar por ochos meses en Cuba, se creó "la Brigada Proliberación José Antonio Galán, con el propósito de impulsar la lucha revolucionaria y organizar el regreso a Colombia... Víctor Medina 
Morón, Fabio Vásquez Castaño, Heriberto Espitia, Ricardo Lara Parada, Luis Rovira, Mario Hernández y José Merchán integraron ese primer grupo" (MeDINA, 2001).

Durante el año de 1963, ubicados en Colombia y luego de realizar trabajo político en la región de San Vicente de Chucurí, el ELN tuvo su mito fundacional el 4 de julio de 1964, con la primera marcha guerrillera en la que 18 personas se encaminaron "con rumbo hacia el noroccidente con el propósito de llegar al Cerro de los Andes" (Medina, 2001). La toma de Simacota en Santander, el 7 enero de 1965, se constituyó en su primera aparición pública. Con el ingreso, en octubre de 1965, del influyente Camilo Torres y su posterior muerte, el 15 de febrero de 1966, el grupo guerrillero logró alcance a nivel nacional. En la década de 1970 amplió su número de combatientes, su capacidad bélica y su alcance geográfico.

Un año antes del nacimiento del ELN, surgió un proyecto liderado por el ministro de Guerra, Alberto Ruiz Novoa, conocido como Acción cívico militar. Buscaba llevar elementos de primera necesidad a las poblaciones más lejanas del territorio colombiano, así como manifestar la presencia militar de los mismos. Es por ello, que se realizaban brigadas de salud, educación, construcción de viviendas y carreteras. Uno de los territorios en los cuales se realizó dicha actividad fue Marquetalia, Tolima, denominado como una república independiente, durante este periodo, por hombres alzados en armas y en donde fue efectivo el primer operativo cívico militar de gran envergadura, conocido como la Operación Soberanía.

Para el momento de la Operación Anorí estaba por finalizar el periodo presidencial del conservador Misael Pastrana Borrero (19701974), último gobierno del Frente Nacional (1958-1974). Durante su administración se consolidó formalmente el grupo guerrillero M-19, tras el supuesto fraude de las elecciones presidenciales de 1970. Esa guerrilla se sumó a los grupos armados de las FARC, ELN y EPL presentes en el país. El 26 de febrero de 1971 "ante las hostilidades de los grupos guerrilleros, y la intención de algunos movimientos universitarios de paralizar actividades sociales, el Presidente declaró el estado de sitio y se concedieron facultades a las Fuerzas Militares". (CAMARGO, 2017). 


\section{El ELN ANTES DE LA OPERACIÓN ANORÍ}

El Ejército de Liberación Nacional se encontraba en pleno proceso de expansión en los primeros años de la década de los setenta. Para 1972 se movilizó al departamento de Antioquia. En enero se llevó a cabo la toma de Remedios, Santa Isabel, y Otú. En febrero el grupo liderado por Ricardo Lara Parada inició una travesía hacia el sur de Bolívar con el objeto de encontrarse con Fabio Vásquez Castaño. El grupo que quedó en la región se encargó de realizar trabajo político en esas poblaciones. Se dividieron en cuatro subgrupos. El primero a cargo de Manuel, alias 'Jerónimo'; el segundo bajo el mando de Antonio, alias 'Emiliano'; el tercero a cargo de 'Noé' y el último bajo la responsabilidad de 'René, cuya función principal fue adelantar tareas de tipo militar (MEDINA, 2001). Los tres primeros se dedicaron a reconocer el territorio, hablar con la población y adelantar el trabajo político de nucleación e incorporación hasta junio del mismo año (MedinA, 2001). Luego se reunieron para valorar el trabajo adelantado. Se dedicó agosto a entrenar al gran número de combatientes recién incorporados. Se reagruparon y subdividieron nuevamente en septiembre para consolidar y ampliar el trabajo político, geográfico y social en la zona. (MedinA, 2001).

Comenzando el año 1973, la columna guerrillera "pasó del lado suroriental de la carretera de Segovia al occidental para buscar a Amalfi [casco urbano], por un costado, y El Bagre y Anorí, por el otro. La región era enorme y entonces nos separamos con el plan de reencontrarnos en el río Porce" (BEHAR, 1985). El grupo a cargo de Manuel Vásquez se instaló en terrenos de Amalfi e inició a trabajar con la población. En ese momento, la cuadrilla más numerosa estaba a cargo de Antonio; otro grupo quedó bajo el mando de 'Noé' y la colectividad de Manuel se ubicó a tres o cuatro días de camino.

En los meses de junio y julio, Manuel Vásquez se movilizó a la quebrada La Gómez, cerca al río Porce (Amalfí). 'Noé' se estableció en El Carmen, territorio de Anorí. El grupo de Antonio se dirigió rumbo a Segovia con la tarea de entrar en contacto con la red urbana de apoyo y buscar comunicación con Fabio.

En la quebrada La Gómez se reunieron los grupos de los hermanos Vásquez Castaño para hacer una evaluación general de la guerrilla que 
estaba colonizando el territorio antioqueño y la seguridad de la zona (MedinA, 2001). En junio se llevó a cabo la toma de Salazar (Amalfi) por parte de un "grupo de treinta guerrilleros para la realización de un operativo militar y de finanzas" (MedinA, 2001). En julio se desplazaron desde Amalfi a la parte de Anorí que limita con Caucasia (desembocadura del río Anorí en el Porce). Allí se unieron los grupos de Antonio y 'Noé'. Por medio de mensajeros se logró la comunicación directa con el grupo liderado por Manuel Vásquez Castaño. De ahí se tomó la decisión de reunir a todos los integrantes en una convención guerrillera en la región de Caucasia. Adicionalmente se determinó el regreso de algunos miembros del grupo de Manuel a la región de Remedios para no perder el trabajo adelantado (MEDINA, 2001).

Este desplazamiento se realizó por un territorio que no había sido transitado por esta guerrilla con anterioridad. El municipio de Anorí ha sido históricamente un terreno topográficamente difícil. Los fuertes caudales de los ríos Nechí, Porce y Anorí, su zona montañosa y las quebradas que se desprenden de dicha conjunción hacen de este un territorio de tránsito intrincado: "[a] la adversidad del terreno y el desconocimiento de este se sumó la temporada de invierno que fue cruda e hizo la zona, habitualmente fría, mucho más inhóspita para una guerrilla proveniente de tierras bajas y cálidas" (UGARRIZA, 2017).

Para ese momento, la columna guerrillera contaba con 110 integrantes de los cuales aproximadamente la mitad no llevaban más de tres meses en la organización: "Si bien no se logró consolidar el trabajo político con la población, lo que repercutirá profundamente en los acontecimientos posteriores, la guerrilla si se reprodujo como estructura militar hasta casi doblarse en número" (MedinA, 2001).

\section{El Comando Operativo No. 10}

En diciembre de 1971 se creó el Comando Operativo No. 10, unidad encargada de coordinar el cerco táctico a la cuadrilla del ELN. Estaba integrada inicialmente por "los batallones Bomboná y Bogotá y con control operacional de nueve bases asignadas a la Policía Nacional. La unidad fue asignada a la V brigada" (CAMARGO, 2017). 
Un año más tarde, en las instalaciones de la V Brigada, con sede en Bucaramanga, el Coronel Hernán Hurtado Vallejo asumió el cargo de comandante de esta unidad. Para ese momento estaba "...conformada por cinco batallones, un componente de la Fuerza Aérea y otro de la Infantería de Marina, la primera forma de brigada móvil que existió en el Ejército colombiano" (MARTínEZ, 2006).

Con el equipo militar organizado para realizar la ofensiva contra el ELN, se trasladó el mando a Barrancabermeja. Allí se detectaron los objetivos de esta guerrilla: "Tomarse militarmente la población de Anorí (Antioquia), dominar la salida al mar por el área de Remedios, Santa Rosa y Otú para alcanzar el Urabá antioqueño con el fin de obtener recursos y armas desde el exterior" (CAMARGO, 2017).

Para evitar estas acciones, el Comando Operativo No. 10 (CO-10) llevó a cabo la Operación Trinitario en la zona del nordeste antioqueño (Quebrada Trinitaria), entre mayo y junio de 1973, y que sería un antecedente de la Operación Anorí. El objetivo principal era la captura de Fabio Vásquez, alias 'Alejandro' (Villamarín, 1999). En general, esta operación es calificada como fallida. Algunas de las razones por las cuales fracasó fue el entrenamiento inapropiado de la tropa, lo que conllevo a cifras bajas de capturas y la superación del cerco por la cuadrilla de Fabio Vásquez Castaño. En junio, el teniente coronel Hernán Hurtado Vallejo decidió comenzar:

Un plan de reentrenamiento en la vereda Fraguas. 'El Conejo', un avezado cazador de Anorí que conocía bien la región le enseñó, durante un mes, a un grupo de soldados a moverse en el monte, a pasar desapercibido y a seguir huellas sin ser descubierto (MARTínEZ, 2006).

El epílogo de la Operación Trinitario sucedió entre el 23 y 24 de junio de 1973. Los soldados Luis Alberto Vivas y José Rodríguez Amón fueron enviados a una tienda veredal a realizar unas compras. Allí, la cuadrilla de 'René' los raptó. Según algunos testimonios, estos soldados fueron torturados y posteriormente asesinados, lo cual generó que se intensificará el accionar de los militares en el área. (BEHAR, 1985). 
DESARROLLO DE LA OPERACIÓN ANORÍ

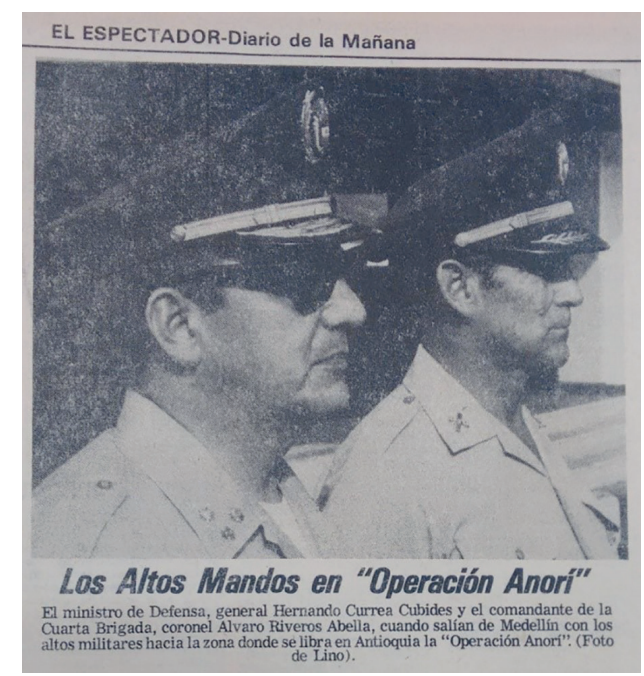

Figura No. 1. Los altos mandos en “Operación Anori'”. El Espectador. 28 de septiembre de 1973.

La periodización de esta operación comprende desde el 7 de agosto (con la emisión de la única Orden de operación No. 036) hasta el 18 octubre con la muerte de Antonio y Manuel Vásquez Castaño. Dicha fecha coincidió "con el traslado o traspaso de la unidad CO-10 de la Quinta a la Cuarta Brigada" (BEHAR, 1985). Recibió el nombre de Operación Anorí en septiembre del mismo año por la prensa: "como la han denominado ya algunos cronistas" (EL ESPECTADOR, 1973) y fue acuñado oficialmente con posterioridad:

En realidad, la operación nunca se preparó con antelación asignándole un nombre, como se hizo, por ejemplo, en Marquetalia o en la Quebrada la Trinidad y tal vez por ello la diferencia de resultados, mucho más positivos en Anorí que en los dos precedentes, al menos en términos de bajas, capturas y retención de material de guerra. (BEHAR, 1985).

El 22 de julio se dio parte al mando operacional del Magdalena Medio de la entrega de 75 guerrilleros en la zona comprendida entre Córdoba y Antioquia. La información oficial aseguraba que los integrantes de las cuadrillas estaban desertando con su equipo armado ante la continua 
desmoralización (CAmargo, 2017). El Mayor Guillermo Robayo afirma que el Coronel Hernán Hurtado Vallejo creía y presentó ante sus superiores que los miembros del ELN se encontraban en Santander con la intención de cambiar su posición geográfica para llegar a Cúcuta cruzando el Magdalena, dando lugar a un "corredor estratégico" (CAmargo, 2017). Lo anterior, lo explicó haciendo uso de acetatos en los que “...Exponía su plan de operaciones. Allí aparecían ya las tropas, no los soldados pintados, sino las unidades y les dijo... 'mi general esto es una campaña y esto es para ganarla y para ello necesito' y empezó su lista..." (CAMARGO, 2017). El Coronel Hurtado Vallejo habló a los presentes sobre pelotones, ubicaciones, reentrenamiento, armamento y finalmente, dijo: "Para poder hacer la operación yo necesito ser el jefe civil y militar en la zona" (CAMARGo, 2017).

Culminada la ubicación de la columna guerrillera, se procedió con el transporte y la logística: "Se inicia la movilización rápida de las tropas, utilizando la carretera que une a Medellín con Yarumal, el ferrocarril de Medellín-Puerto Berrío, el transporte fluvial del río Nechí y el transporte aéreo, utilizando el aeropuerto de Amalfi y unos helipuertos construidos en Anorí, Zaragoza, Tamí, Cedeño y Pato" (Hernández, 2004).

\section{ESTRATEGIAS MILITARES}

En términos generales toda la operación se hizo bajo la premisa de tres estrategias militares: Yunque de Martillo, Plan Cazador y Plan Hogar. El primero consistió en que fuerzas de presión realizaran un hostigamiento sobre el grupo guerrillero, quien en su retirada era contraatacado por la retaguardia con otro grupo. Hurtado Vallejo lo planteó en los siguientes términos:

Las fuerzas de presión, que son la contraguerrilla, los movieron y empezaron a tomar contacto. Ellos se corrían muchas veces a la topa tolondra, y se encontraban con nuestras tropas de cierre -eso se llama Yunque de Martillo, una tropa persigue y la otra tranca por la vía de escape- que los hacían andar erráticamente (BEHAR, 1985).

La implementación de este tipo de estrategia conlleva al sometimiento de la tropa a un estado de desgaste continuo, que puede afectar los resultados. Con el fin de lograr un mejor desempeño, el comandante del CO-10 relevaba sus tropas con regularidad: 
Las patrullas eran embarcadas en el helicóptero para que llegaran a las zonas álgidas descansadas y pudieran continuar la persecución o hacer el bloqueo requerido sin problemas, mientras las otras tropas se recuperaban. Se trataba de ahorrar esfuerzos, los soldados caminaban, patrullaban y vigilaban lo necesario... No es lo mismo una patrulla agotada que unos hombres con fuerzas renovadas para el combate (MARTínez, 2006).

En cuanto al Plan Cazador, consistía en "infiltrarse y no ser detectado. Dicha actividad se realizaba de noche o a campo traviesa si era de día. El siguiente paso era alcanzar el objetivo sin ser detectado, observar sin ser observado, para luego golpear y retirarse por una vía diferente" (VILlamarín, 1999). Era usual que el plan cazador incluyera el seguimiento de huellas.

Por su parte, en el Plan Hogar se dejaba "soldados escondidos cerca o durmiendo dentro de las casas con la misión de suministrar información tan pronto se produjera presencia de los bandoleros. Cuando el helicóptero sobrevolara el área, aquellos agentes de inteligencia deberían colocar sábanas o señales preconvenidas sobre los techos de las casas para comunicar al comandante de la operación que estaba cubierta la ruta de repliegue guerrillero" (VILlamarín, 1997). De esta forma, se aprovecharon al máximo las falencias de aprovisionamiento de los grupos guerrilleros: "En donde se sabía que desesperados por la carencia de víveres llegaban los bandoleros a reabastecerse, para atacarlos por sorpresa en un sitio que consideraban seguro (VILLAMARÍn, 1999).

Es necesario mencionar el famoso cerco táctico. Respecto de esta estrategia el Coronel Hurtado manifestaba que:

"En operaciones, hablar de cercos es una fantasía, los cercos no se extienden, cerco no hay; uno controla con puestos de detención los puntos críticos y hace permanentes hostigamientos al enemigo para obligarlo a moverse. Al tomar estas medidas, los colocábamos en posiciones muy inciertas, adonde llegaban nos encontraban, si torcían hacia el río encontraban tropa" (BEHAR, 1985).

Complementando lo anterior, se instauró la clave Cóndor en el aire. Esta corta frase: "Que equivalía a la orden de silencio total de radios" (VILlamarín, 1999), permitía el apoyo de "otra contraguerrilla [que] 
automáticamente embarcaba el helicóptero ya prendido, para caer en el punto crítico del encuentro. Se controlaba todo, cuando era necesario, desde el comando del CO-10 hasta cuando se regularizaba la situación" (CAmargo, 2017, p.61).

Los PRimeros Combates. Agosto y SEPTIEMBRe De 1973.

"Fueron 72 días de incesante persecución sobre un tramo de casi 700 kilómetros..." (VILlamaRín, 1999).

En agosto de 1973 se dividió nuevamente la columna guerrillera de los hermanos Vásquez en tres. El primer grupo de 10 hombres, bajo la responsabilidad de 'Alonso', procuraría entrar en enfrentamientos, en la zona del río Anorí hacia el Porce, con el Ejército, buscando distraerlo para permitirle al grueso del grupo encontrar a Fabio Vásquez (MEDiNA, 2001). El plan consistía en que a los 20 días alcanzaría a los otros dos grupos siguiendo la ruta que estos iban a recorrer y a través de los enlaces que se les fueran dejando. La segunda agrupación, a cargo de Manuel Vásquez y de 13 personas, incluido 'Noé', se dirigiría hacia el occidente, con la intención de salir a Puerto Valdivia. El tercer grupo, de 51 personas aproximadamente y a cargo de Antonio Vásquez, debía seguir la misma ruta del segundo, pero en forma más lenta.

Por su parte, el Coronel Hurtado Vallejo manifestó algunas indicaciones: "El 8 de agosto ordené a las compañías Dragones y Anzoátegui, de los Batallones Colombia y Bomboná, instalar dos puestos de cierre en los puentes de La Caída y El Toro" (MarTínez, 2006). Durante este mes se llevó a cabo la instalación del puesto de mando del CO-10 en Cerro Bolívar. Por medio de las labores de inteligencia, las Fuerzas Armadas lograron determinar los movimientos y la estrategia del grupo guerrillero antes de terminar el mes de agosto:

“...Se confirmó la información que Antonio y Manuel Vásquez se movieron del sector de El Carmen por un sitio denominado Brechas hacia la quebrada La Trinidad, pero a la vez dejaron un grupo de nueve hombres encabezados por Nelson, para que hiciera presencia sobre la quebrada Las Cruces y sirvieran de seguridad en la retaguardia del grupo principal" (VILlamarín, 1999). 
El primero de septiembre, inclusive antes de que iniciaran los combates, se registró un considerable revés para el operativo. 14 soldados resultaron muertos a causa del choque de su embarcación contra un tronco de madera cuando realizaban actividades de patrullaje. El suceso se registró sobre el río Nechí, "a la altura del sitio denominado Santa Bárbara entre las localidades de El Bagre y Zaragoza" (El Colombiano, 1973). En total, se movilizaban 45 unidades del Ejército pertenecientes al batallón de Infantería No. 18 Rooke.

Para empeorar la situación, días después el Coronel Hurtado determinó que el ELN había logrado burlar el primer cerco tendido. Verificado el desacierto, se tuvo que trasladar todo el dispositivo: "Cerca de 800 hombres debían caminar en el menor tiempo posible para evitar la huida del ELN. ¿Si ellos lo hicieron tan rápido por qué nosotros no podíamos hacerlo? En doce horas, a pie y en helicóptero, movilizamos 840 hombres" (MARTínez, 2006).

Llegado el 9 de septiembre, el grupo más numeroso dentro de la guerrilla contaba con 49 guerrilleros, de los cuales 10 se encontraban en un estado de franca desmoralización. El relato aportado por 'Armando Martínez' pone de manifiesto la decisión de enviar a casa a los integrantes desanimados, pero luego de cruzar el río Nechí (BEHAR, 1985). Ese mismo día se presentó un choque entre el grupo de contraguerrilla Indio, adscrito al batallón Colombia, y el grupo de seguridad del ELN. Allí se dio de baja a Juvenal, "resultó herido un suboficial, fue recuperado un fusil con abundante munición y decomisaron siete morrales hechizos en los cuales los elenos llevaban las pertenencias y documentos" (VILLAMARÍN, 1999). Para ese momento el grupo guerrillero tomaba conciencia de la magnitud del operativo: "Ya teníamos pistas de lo que se nos venía encima, pues desde las seis de la mañana veíamos y oíamos cómo los helicópteros descargaban Ejército al frente" (BEHAR, 1985).

Dos días después se presentó un ataque al grupo de Antonio Vásquez que terminó dividido en dos. Este combate dejó un soldado muerto (VILlamarín, 1999). A su vez, retornaron por término de la comisión del servicio, el batallón Boyacá a Pasto y el batallón Colombia a Tolemaida. (Villamarín, 1999). El 13 de septiembre, Manuel y sus acompañantes recibían, por radio, la noticia de la muerte de alias 'Francisco', integrante de su grupo, que quedaba con nueve guerrilleros (MEDINA, 2001). 
El grupo de Antonio llegó el 16 de septiembre a un lugar en “donde podían cruzar el río Nenchí [sic], que estaba manso y bajito; sin embargo, como dos hombres quedaban atrás y no sabían nada de Jerónimo, decidieron que una columna armada pequeña se devolviera y buscara a los otros" (Hernández, 2004). Debido a que esa noche llovió intensamente, al día siguiente fue imposible cruzar el río. La situación se complicó rápidamente debido a la delación de un campesino. Con esta información "el enemigo los ubicó y la patrulla que estaba adelante se regresó para salirles por detrás. Cuando se intentó cruzar nuevamente el río, un helicóptero les descargó patrullas al frente" (HERNÁNDEZ, 2004). Finalmente, dos guerrilleros lograron cruzar el río, pero quedaron aislados de la colectividad. El grupo se vio obligado a retroceder su marcha y quedó reducido a 32 integrantes.

El 20 de septiembre cayó 'Noé'. Al otro día, se encontraron los grupos de Manuel y Antonio por azar. Las Fuerzas Armadas propinaron el golpe más duro a la organización guerrillera. Murieron seis guerrilleros y 10 más fueron capturados (MEDINA, 2001).

El 23 de septiembre la compañía Hiena del batallón Pichincha, a cargo del Teniente Carlos Escobar, dio de baja a alias 'Roberto', en la quebrada San Antonio (Villamarín, 1999). Al día siguiente, la misma unidad capturó a 'Dairo' y 'Armando' e incautaron un fusil ametrallador y fusil de perilla. Por su parte, la compañía Arpón, del batallón Rooke, dio de baja a alias 'Javier', quien portaba una pistola 7.65. (VILLAMARÍN, 1999).

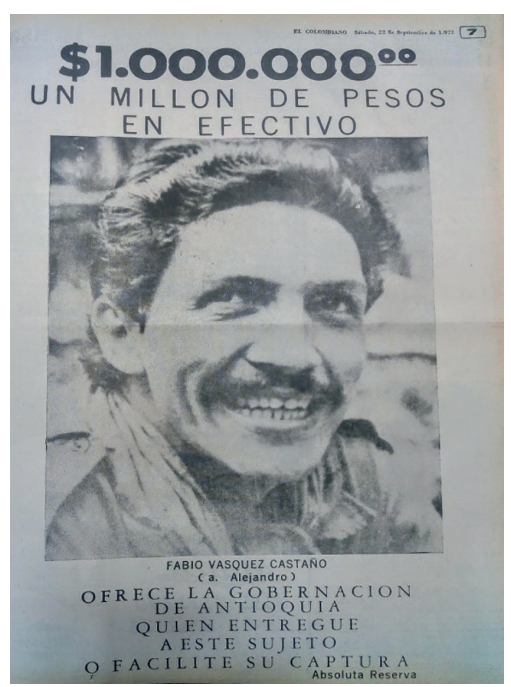

Figura No. 2. Un millón de pesos en efectivo. El Colombiano. 22 de septiembre de 1973. 
Para esta época el Ejército pudo corroborar, por medio de varias fuentes recuperadas en combate y algunas declaraciones de capturados, que "en la zona del Magdalena Medio actúan cuatro grupos, el principal comandado por Fabio Vásquez Castaño y los otros tres por el sacerdote español Domingo Laín, el bachiller Ricardo Lara Parada y Antonio Vásquez Castaño" (CAMARGo, 2017).

El 24 de septiembre, se informó la anexión de "un refuerzo de 1.200 hombres especializados en este tipo de operaciones, en momentos que guerrilleros capturados afirmaron que la situación era precaria para los alzados en armas" (CAMARGO, 2017). Con este refuerzo ya eran 10 las compañías que participaban en la operación militar. "Se ha establecido un cerco total con apoyo de helicópteros. 17 guerrilleros han sido muertos en los últimos días, y unos 10 han sido capturados, entre ellos un cura -Luis Zabala Herrera- y un niño de 10 años" (CAMARGo, 2017).

El 26 de septiembre la compañía Bolívar presenció un intercambio de disparos quedando herido alias 'Alcides', quien estaba armado con una pistola calibre 45. Fue transportado en helicóptero al hospital de Anorí en donde murió (Villamarín, 1999). Por su parte, la compañía Búfalo del batallón Rooke tendía una emboscada instalada sobre la quebrada La Trinidad en la vereda Media Falda. El 27 de septiembre fue dado de baja en ese lugar alias 'Horacio' (Villamarín, 1999). En los dos días siguientes se presentaron las capturas de 'Rigoberto' y 'Gildardo', en la quebrada La Usura, y Pastor, en Manichiquito; y de alias 'Rafael' y 'Albeiro', en el cruce de las quebradas La Plancha y San Antonio (Villamarín, 1999).

En horas de la mañana del 27 de septiembre "visitaron el puesto de mando del CO-10, instalado en la vereda La Primavera, el General Álvaro Herrera Calderón, comandante del Ejército; el General José Vargas Sierra, jefe del Estado Mayor Conjunto de las Fuerzas Militares, y el comandante de la Fuerza Aérea" (Villamarín, 1999). La visita denotaba un cierto aire de triunfalismo por la operación. De allí en adelante el propósito principal se concentró en dar de baja a los hermanos Vásquez, de quienes cada vez se obtuvo información más detallada. 


\section{El DESENLACE. Los ÚLTIMOS DÍAS de MANUEl y ANTONIO VÁSQUEZ CASTAÑo}

Era más o menos la una de la tarde, cuando en el radio se escuchó el consabido "cóndor en el aire" -Aqui Garibaldi 6 -contesté. -Acabamos de encontrar el rastro de 3, rumbo a la quebrada La Usura. El teniente Ospina le dio una patada al sancocho

y rodó la olla falda abajo. Corrió a subirse al helicóptero y al ratico sonaron tres tiros. No son tres bandidos les dije, por radio, son Manuel, Antonio y la otra es una mujer, es Lucía. Los acabamos (MARTínez, 2006).

El grupo del ELN se encontraba completamente disperso. No lograba comunicarse con los apoyos urbanos a pesar del envío de varios emisarios. Tampoco tenía la capacidad para contrarrestar un ataque de las Fuerzas Armadas. Sin embargo, debido a que ya era un grupo reducido sus movimientos fueron cada vez más difíciles de rastrear. Aun así, el apoyo de los campesinos y la información de primera mano de los capturados permitieron hacer un cerco cada vez más pequeño alrededor del grupo.

Octubre se constituyó como el principio del fin. El primero se verificó un contacto armado en la finca La Primavera de la vereda Concha Media, entre el grupo de los hermanos Vásquez y la compañía Tigre del batallón Pichincha. También se presentó el choque con uno de los reductos del ELN en la vereda Santa Inés y la compañía Arpón del batallón Bomboná.

Al mismo tiempo en que se instalaba el puesto de mando del CO-10 en Madreseca, fue dado de baja alias 'Tito', mensajero de Manuel Vásquez, cerca al nacimiento de la quebrada Santiago. En esta acción se decomisó un fusil G-3, una granada de fragmentación, proveedores y munición (Villamarín, 1999).

Esta primera semana de octubre puso en evidencia la ansiedad de la dirigencia de las Fuerzas Armadas por lograr el golpe final. Así, por medio de la regencia de Riveros Avella el 4 de octubre "entraron 
a operar al área de Segovia y Zaragoza dos compañías de fusileros del batallón Voltígeros, distinguidas con los indicativos Trinquete y Tijereta" (VILlamarín, 1999).

El 5 de octubre el CO-10 movió nuevamente su lugar de operaciones al pasar a Remolino. Dos días después, la compañía Arpón obtuvo información de algunos pobladores que habitaban cerca de la quebrada La Tona sobre el paso del ELN por ese lugar. Hurtado Vallejo ordenó "la colocación de una unidad del batallón Bomboná sobre la desembocadura del río Matas en el río Porce, con las misiones específicas de bloqueo y patrullaje lineal desde ese lugar hasta la desembocadura del Porce, sobre el río Nechí" (VILlamarín, 1999).

El 9 de octubre se presentaron nuevos enfrentamientos. Fue aprehendida 'Rubiela' con una carabina M-1 y 140 cartuchos (VILlamarín, 1999). Con el testimonio de la recién capturada, el organismo militar determinó que para la fecha, el grupo madre estaba compuesto por "Efrén, Faber, Heriberto, Rocío, Lucía, Jerónimo y Emiliano, y portaba en total cinco carabinas y dos fusiles" (VILLAMARÍN, 1999).

Por su parte, el Teniente Carranza, comandante del elemento Comandos de Selva de la Infantería de Marina, con el ánimo de transportar tropas y heridos, coordinó con el piloto de uno de los helicópteros el aterrizaje en una zona muy complicada: "El problema radicó en no existir ni un solo tramo de ribera sobre el río que permitiera el aterrizaje de la aeronave. Solo las aguas del Porce y una gran piedra que sobresalía de ellas muy cerca de la orilla" (CARRANZA, 2011,). Con gran destreza, el helicóptero logró aterrizar sobre la piedra:

"y pidió por radio que los botes lo escoltaran. Una vez hecho esto, los hombres que estaban en tierra colocaron un palo que sirvió de puente por donde subieron los soldados... Después del primer helicóptero, le siguieron otros cuatro más, en los que se transportaron además de unas patrullas, varios heridos que requerían atención urgente" (CARRANZA, 2011).

Ese mismo día, la compañía Lince capturó a Liliana. Debido al vigor del combate, "el comandante de la patrulla dejó a la guerrillera sola cuidando a [un] suboficial herido" (VILlamarín, 1999). Más adelante se abordará la forma en la que la detenida logró salir de la zona de operaciones con rumbo a la base militar. 
A mediados de octubre se incorporaron nuevamente unidades. En total fueron tres grupos de contraguerrillas "entrenados por el batallón Girardot en Medellín y el batallón Ayacucho en Manizales" (VILlamarín, 1999). Hurtado Vallejo se apoyó en el uso de helicópteros para coordinar una nueva arremetida "al oeste del río Tenche desde la quebrada Quebradona hasta la quebrada San Agustín, con tropas de los batallones Rooke, Pichincha, Bomboná y Voltígeros, mientras las dos unidades comprometidas con la persecución continuaron el seguimiento de las huellas dejadas por el grupo" (Villamarín, 1999). Así, el 15 de octubre "fueron capturados por la compañía Arpón en límites entre la quebrada Quebradona y el río Tenche, 'Wilson' y 'Faber', quienes llevaban consigo dos carabinas y 234 cartuchos" (VILlAmarín, 1999). Debido a ello, el grupo madre quedó reducido a seis personas: 'el tío Efrén', 'Heriberto', 'Lucía', 'Rocío' y los hermanos Manuel y Antonio Vásquez Castaño. Los días siguientes la compañía Arpón dio de baja a alias 'Heriberto' y decomisó un fusil (Villamarín, 1999). En este punto, el Coronel Hurtado Vallejo manifestó la importancia de los equipos aéreos en su estrategia militar:

"Acostumbré a ir en el helicóptero hasta el lugar de desembarco de las patrullas, que adelantaba sobre el terreno para esperar los reductos cada vez menores del eln, sobrevivientes a los combates. No puedo olvidar el impacto sicológico que produce la tensión de abordar la aeronave a sabiendas que existen altas posibilidades de enfrentamiento con un enemigo impreciso y escurridizo..." (VILlamarín, 1999).

El 17 de octubre se verificó la captura de Adelfa Fierro, alias 'Rocío'. Según varios relatos, Manuel es quien le pide que se entregue "con la misión de llevarle a la organización el informe de cómo fueron los últimos acontecimientos" (Medina, 2001). Tan solo dos horas después, un pelotón de la compañía Búfalo dio de baja a uno de los combatientes más experimentados de la guerrilla, quien además estaba encargado del grupo de seguridad, el 'tío Efrén'. Respecto a esa baja, el Coronel Hurtado Vallejo manifestó: “sin el 'tío Efrén' fue el acabose, porque era el hombre más valiente que tenían” (BEHAR, 1985).

El 18 de octubre se puso fin a los combates con las bajas de los tres últimos integrantes del grupo madre. Los hermanos Vásquez Castaño 
y alias 'Lucía' fueron ultimados por parte del segundo pelotón de la compañía Hiena y la contraguerrilla Lince 6 (VILlamarín, 1999). "Con la muerte de los hermanos Vásquez Castaño prácticamente los operativos de Anorí llegan a su fin. Pese a lo anterior el Ejército siguió realizando patrullajes en la búsqueda de lo que consideraban los últimos reductos de la organización guerrillera" (Medina, 2001).

No existe un consenso sobre el balance de esta operación. Por una parte, las cifras propuestas por el ELN registran "la realización de 39 combates, con 178 bajas causadas al Ejército entre oficiales, suboficiales y soldados y más de 400 heridos. La guerrilla tuvo 27 bajas en los dos meses de combates de agosto a octubre" (Medina, 2001). Sin embargo, esta cita no cuenta con fuentes que la respalden. El Ministro de Guerra en Memorias al Congreso de 1974 presenta un cálculo general sobre las muertes y capturados en orden público durante 1973. Allí, se menciona que durante agosto, septiembre y octubre se dieron de baja a 35 antisociales (así lo menciona el informe) y 46 fueron capturados. Por parte de las Fuerzas Armadas admiten nueve bajas (MINISTERIO DE Defensa Nacional [Mindefensa], 1974). En la prensa se dictaminaron otras cifras. Vanguardia Liberal reseña que "en la región de Anorí fueron dados de baja unos 30 integrantes del grupo guerrillero, otros 26 se entregaron, entre ellos un sacerdote católico, y varias mujeres y niños" (CAMARGO, 2017). El Colombiano (1973), en informe del 20 de octubre, refiere que "el saldo conocido de la 'Operación Anorí' es de 26 guerrilleros muertos, 36 capturados y varios extraviados en la montaña". De acuerdo a la investigación, las cifras más convincentes son las suministradas por la prensA.

\section{EL PAPEL DE LA FUERZA AÉREA}

En el apartado anterior se expuso un panorama general sobre la participación de la Fuerza Aérea Colombiana en la Operación Anorí. Entre sus actividades resaltan: el transporte aéreo de tropa y del comandante del CO-10, coronel Hernán Hurtado Vallejo; el abastecimiento de víveres y enseres para los militares; los vuelos de reconocimiento y la evacuación de heridos y muertos de la zona.

Con respecto a los equipos empleados por parte de la $\mathrm{FAC}$, el comandante del ELN Milton Hernández en su libro Rojo y Negro (2004) 
afirma que: “...La fuerza aérea puso a disposición el comando aéreo número dos, equipado con varios aviones de reconocimiento y transporte U-6A, C-47, DC-3; el batallón aéreo transportado General Serviez y 16 helicópteros Iroquois". Esta afirmación se menciona nuevamente en el libro ELN: una historia de los orígenes de Carlos Medina Gallego. Sin embargo, la información suministrada no es corroborada en los textos que emplean fuentes militares, con la excepción de los helicópteros Iroquois.

De acuerdo con la información oficial, los helicópteros Iroquois usados en el país tienen la tipología "UH-1B, HUEY UH-1H/AH-1H” (ForERO, 1994). Fabricados en EE. UU., llegan a la Fuerza Aérea Colombiana en 1963. A pesar de las similitudes en su estructura, los dos modelos se diferencian en sus funciones para reconocimiento armado o ataque aéreo: " $\mathrm{El} \mathrm{B}$ puede transportar sus dos tripulantes y siete soldados armados y equipados o tres camillas con dos enfermos. La versión $\mathrm{H}$, lleva sus dos pilotos y 13 soldados o seis camillas con dos enfermos" (ForERO, 1994). Han sido empleados en diferentes eventos no solo de índole netamente militar, sino además, en apoyo a la población civil. "La capacidad máxima externa en gancho es de 3.000 lb., en versión B y de 4.000, en la H”' (ForERO, 1994). A continuación, una fotografía de los helicópteros en mención.

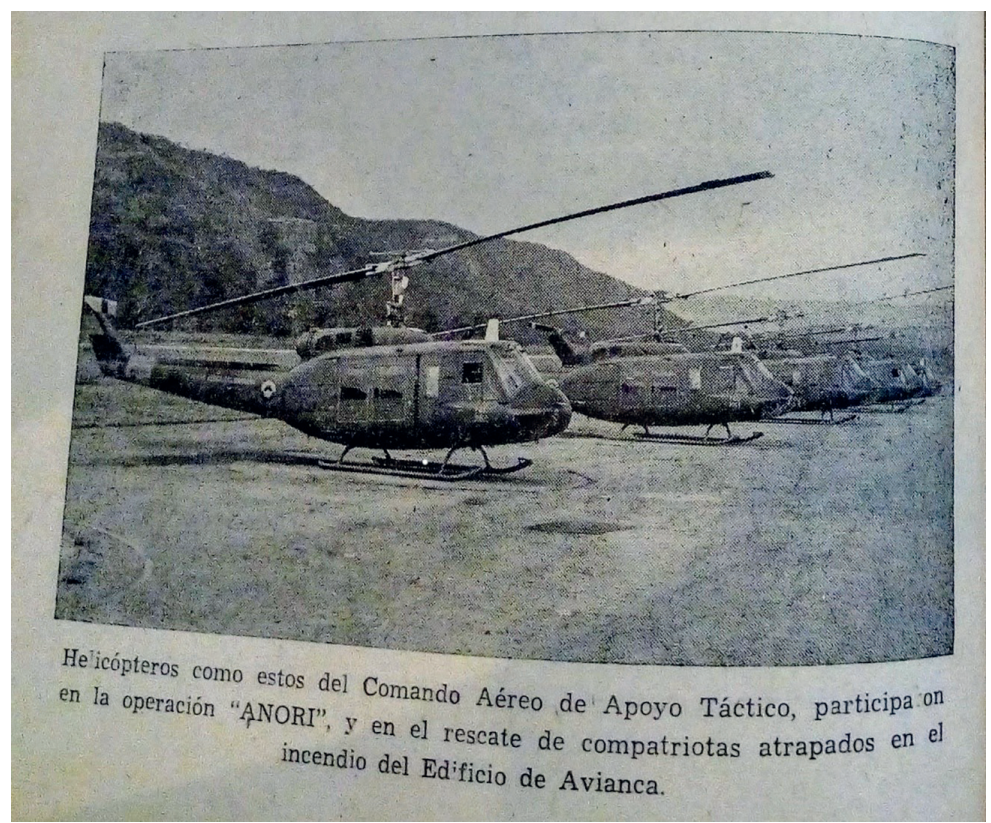

Figura No. 3. Helicópteros de Apoyo Táctico. Mindefensa. 1974. 


\section{MOVIMIENTO DE TROPAS Y HERIDOS MILITARES}

Es común en los textos consultados resaltar la importancia de la Operación Anorí por su estrategia al cercar a su contrario mediante el uso de tropas por tierra, aire y conexiones fluviales. Equipo que además trabajó conjuntamente para lograr los objetivos planteados desde su inicio, dando lugar a narraciones que destacan las actividades y el rol de cada una de las tres ramas de las Fuerzas Militares. A continuación, presentamos algunas impresiones sobre el papel de la Fuerza Aérea Colombia y sus principales aportes en el traslado de heridos y tropa.

En una entrevista realizada al Mayor Patiño por los autores del libro Fuerzas Militares de Colombia Ejército Nacional II División: el conflicto armado en las regiones, él asegura que la Fuerza Aérea fue de vital importancia por “...la utilización de los helicópteros para observación, para movimientos de tropa [y] heridos, para el traslado de los prisioneros hacia la ciudad de Medellín y los relevos para el personal y el resto de apoyos internos" (CAMARGO, 2017).

Impresión compartida por el entonces Oficial Julio César Carranza. Como Teniente a cargo del Elemento de Comandos de Selva, acompañó la Operación mediante la navegación día y noche del río Porce. En medio de su misión valoró el trabajo de la FAC aseverando que los pilotos de la Fuerza Aérea "sin otra pista o zona de aterrizaje que no fueran las grandes rocas que sobresalían del agua, se atrevieron a posar sus naves para mover patrullas, sacar heridos, así como para abastecerlos de urgencia" (CARRANZA, 2011).

El trabajo estratégico que permitió una labor conjunta entre las tres esferas militares es de resaltar. Cada una de ellas aportó de forma trascendental ya fuera en el bosque, por los móviles en tierra, en los botes por el río Porce, gracias a la Infantería de Marina, o mediante el apoyo de la FAC, quienes haciendo uso de helicópteros apoyaban "en el posicionamiento de las patrullas" (CARRANZA, 2011). 


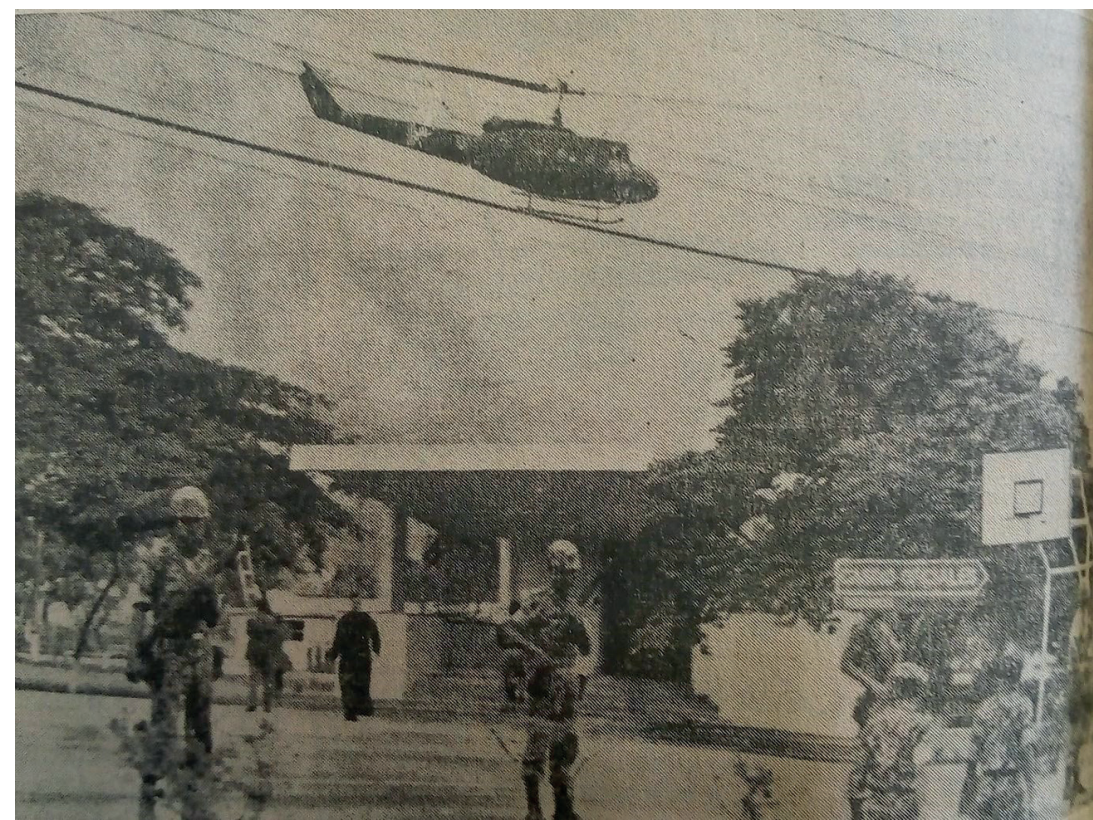

Figura No. 4. Hacia el cementerio. El Colombiano. 20 de octubre de 1973.

\section{El transporte del Coronel Hernán Hurtado Vallejo}

Los helicópteros de la Fuerza Aérea Colombiana apoyaban además las labores tácticas mediante el traslado por el territorio antioqueño del Coronel Hernán Hurtado Vallejo. Un fragmento de su labor consistió en la relación que construyó con la población civil. Como respuesta a esa actitud, "muchos campesinos habían aceptado de buena gana tener en sus fincas soldados vestidos de civil (...) Cada una de estas c[a]sas estaba marcada con un pañuelo blanco en el techo, de manera que las podíamos distinguir desde el helicóptero" (MARTínez, 2006). Estos sobrevuelos, más la labor en tierra, consolidaron la continua persecución de los miembros del ELN sin que ellos sospecharan de la complicidad de los pobladores. Además, el uso de las aeronaves era constante por parte del Coronel Hurtado Vallejo, como él asegura:

“...Yo iba en el helicóptero detrás de ellos [ELN], cada vez que encontraban una huella, prendían una fogata con ramas verdes y se levantaba una humareda blanca, yo tomaba el azimut, el ángulo con 
el que huían, establecía las posibles rutas de escape y desembarcaba patrullas descansadas en el camino para que les bloquearan el paso" (MARTíneZ, 2006).

El equipo aéreo llevaba al comandante del CO-10 y, siguiendo sus órdenes, movilizaba a la tropa cada vez que fue necesario. Así ocurrió a finales de septiembre tras recibir información sobre la cercanía de cuadrillas del ELN, "El CO-10 movió tropas helicoportadas hacia las quebradas La Trinidad, Juntas, San Andrés y El Roblal” (CAMARGO, 2017).

De acuerdo con la información suministrada, los pilotos de la FAC desempeñaron un comportamiento ejemplar frente a las órdenes del coronel Hurtado Vallejo. Sin embargo, en diversas ocasiones fue difícil seguirlas por el alto riesgo que implicaba para su seguridad. Así sucedió días antes de la muerte de 'Noé', en septiembre de 1973, tras encontrar una carta que fue dejada por otro grupo del ELN:

"Tenía que verificar la información, y sobre todo, saber a ciencia cierta hacia dónde se dirigían. Nos fuimos con la última caneca de combustible que quedaba (...) El piloto aterrizó a regañadientes y esa noche nos quedamos en una casita, mirando, mirando. Ahí supe que iban en carrera hacia la vereda Santiago. Instalé dos puestos de cierre y dos días después ellos chocaron con nosotros y dimos de baja a alias Noé, uno de los más aguerridos jefes del ELN" (MARTíneZ, 2006).

Luis Alberto Villamarín (1999) asegura que en la Operación Anorí, más que la coordinación táctica a alto nivel fue la conducción operacional, así como la flexibilidad táctica en dicha tarea las que influyeron en el resultado final. Por ello "...Los helicópteros fueron fundamentales en el desenlace de los combates".

\section{TRASLADO DE MIEMBROS DEL ELN}

Los integrantes del ELN experimentaron la participación de la Fuerza Aérea Colombiana mediante la visualización de los helicópteros, intento de tiroteo $\mathrm{y}$, si fueron capturados, heridos y/o muertos, mediante su trasladado en los mismos. 'Armando Martínez', sobreviviente de Anorí, resalta la extensión del equipo militar por su volumen y el trabajo de los soldados despejando el área "[...] hasta de una hectárea en esos montes para que los helicópteros pudieran aterrizar” (BEHAR, 1985). 
Aquellos elementos según Milton Hernández (2004) eran vistos por la cuadrilla del ELN con extrañeza, por ello afirma que el 12 de septiembre tras un intento de persecución "... Se tiroteó un helicóptero (no se tenía ninguna experiencia al respecto, se sentía cierto temor a este tipo de aparatos)". En palabras del autor, ese suceso fue significativo para los combatientes.

En algunas ocasiones el traslado de tropas obedeció a información suministrada por capturados del grupo guerrillero. Por ejemplo, el 27 de septiembre, tras la aprehensión de 'Gloria', fue posible nueva información con la cual "[...] se transportaron de inmediato tropas en helicóptero, para instalar cierres sobre el eje de avance del grupo que errante buscaba con desespero salir del dispositivo tendido por el CO-10" (VILlamarín, 1999).

El transporte de caídos en combate fue otra labor ejercida por la FAC. Es el caso de los cuerpos de los hermanos Vásquez Castaño, que fueron llevados a Medellín para su reconocimiento. El 20 de octubre, dos días después de su muerte, los altos mandos deciden enterrarlos en un lugar secreto para evitar desórdenes públicos. Por ello viajaron a bordo de "helicópteros de la FAC y se trasladaron a la región noreste de Antioquia en un vuelo de 45 minutos. Con ellos llevaban los dos rústicos cajones donde estaban los cuerpos de Manuel y Antonio Vásquez Castaño" (EL ESPECTADOR, 1973).

\section{DenunCias SOBRe Violación De DeRechos Humanos}

Como parte integral de esta investigación se han encontrado denuncias sobre excesos por parte de las Fuerzas Militares ${ }^{4}$ y el ELN en el nordeste antioqueño. Dentro de este apartado se indagó sobre las denuncias relacionadas con la Fuerza Aérea y se verificó, hasta donde fue posible, la veracidad de las mismas.

El primer caso corresponde a una denuncia del diputado Gilberto Zapata Isaza ante la Cámara de Representantes y el Ministro de Defensa, el 13 de septiembre de 1973. El diputado expone que debido a excesos de las Fuerzas Militares, en Amalfi se vivieron momentos de angustia a finales de julio o junio (menciona los dos meses en aparente confusión). Militares revelan secretos sobre operaciones militares (II). La Operación Anorí. (1975). Alternativa
del pueblo, (36). 
El relato continuó: “... Dos helicópteros de las Fuerzas Armadas, las mismas que están bajo su comando, exhibieron los cuerpos colgantes de dos campesinos, el uno atado de los pies, el otro con un lazo o soga debajo de los brazos y giraron varias veces sobre el centro de Amalfi. Todo el pueblo vio horrorizado cómo colgaban a esos campesinos que eran tildados de guerrilleros! (sic)" (FCSPP, 1974). El discurso siguió con un llamado a honrar de forma correcta la institución militar y a respetar la vida e integridad de la población, independientemente de su actividad social, política o militar.

En sintonía con esta grave acusación, la diputada Gilma Valencia en la Asamblea Departamental de Antioquia denunció casos de tortura en la población de Urrao, Antioquia. En su testimonio agrega: “... Otros diputados denunciaron también que algunos detenidos en la represión militar de Anorí y Bajo Cauca fueron lanzados desde helicópteros militares" (FCSPP, 1974). Este relato aparece también en algunos de los textos consultados: "Se ve lanzar campesinos desde los helicópteros o despedazarlos contra los copos de los árboles colgados de una pierna" (HERNÁNDEZ, 2004).

En la revisión de prensa se encontró un texto que hacía alusión a este tema. Dentro del periódico El Colombiano (1973) del 20 de octubre se publicó el informe especial Por errores tácticos cayeron los Vásquez Castaño, realizado por Javier Velásquez Yepes. Allí, un apartado titulado El caso de los 'arrojados' desde los helicópteros aborda esta denuncia: "En esa época - primera quincena de agosto- los habitantes de Anorí empezaron a observar cómo los helicópteros pasaban sobre la población con "personas colgadas de los aparatos". Más adelante, se manifiesta la explicación de estos sucesos por parte de portavoces militares:

Se trata del método de constante utilización, en el mar y en la selva, cuando no se dispone de helipuertos (...) El helicóptero realiza un vuelo estacionario sobre determinada zona y se lanza un cable en cuya punta hay una "silla" con el objeto de poder izar a las personas que requieren auxilio o necesitan ser movilizadas por alguna razón. Esta tarea, que diariamente se ejecuta con integrantes de la tropa, fue empleada en varios casos, para evacuar cadáveres o para trasladar guerrilleros (EL Colombiano, 1973). 
Se encontró además una alusión al transporte de personas por medio de esta modalidad. El Coronel Hurtado Vallejo, comentando el caso de 'Liliana', capturada el 9 de octubre, manifestó:

"Fui en helicóptero hasta el sitio, pero la densidad del bosque a duras penas dejaba espacio para extraer una persona izada con una soga. Liliana recibió el lazo y lo acomodó en su delgada humanidad. El helicóptero levantó con la joven asida a la cuerda. El aterrizaje de la nave en la base militar fue espectacular. En la medida que la nave iba tomando colocación para posarse en tierra, el menudo cuerpo de Liliana hacía elongaciones pendulares... varios soldados detuvieron el movimiento pendular del cuerpo suspendido, la ayudaron a descender al piso y permitieron un nuevo decolaje de la nave con dos soldados para rescatar de manera espectacular también al sub-oficial que herido quedó solo esperando la evacuación" (VILLAMARíN, 1999).

Faltan más elementos para poder esclarecer este tipo de denuncias. La ausencia o desorden de archivos judiciales y legislativos no permitieron conocerlas de primera mano. La historia oral y/o la visita a archivos locales podrían arrojar más luz sobre esta situación.

\section{CONCLUSIONES}

A lo largo de este texto se explicaron las diferentes versiones de la Operación Anorí, aquellos datos que permiten comprender la magnitud de este suceso, así como la participación de los actores en conflicto y la influencia ejercida por la población civil y la geografía nacional.

A través de la investigación se pudo corroborar que la temporalidad de la Operación Anorí fue entre el 7 agosto y el 18 de octubre de 1973, que finalizó con la muerte de los hermanos Vásquez Castaño y 'Lucía'. Por otra parte, se encontró que las cifras sobre los muertos en combates, heridos y capturados no son del todo convincentes. Infortunadamente no se encontró un reporte oficial que diera cuenta sobre los datos consolidados de esta Operación.

Dentro del entramado de explicaciones encontramos dos posturas hegemónicas que por momentos tienden a ser contrarias, debido a la posición desde la cual se narra el acontecimiento. El ejemplo más claro para entender lo anterior es la disparidad en las cifras sobre las bajas, 
heridos y capturados del grupo guerrillero. Este problema también se hizo visible en los datos de equipos y personal de las Fuerzas Armadas. Inclusive se encontraron disensos sobre algunas fechas o acontecimientos. En medio de los contrastes, se posibilitó la recopilación de los datos presentados con anterioridad. No deja de ser relevante resaltar las dificultades de acceso a algunas fuentes de información, que en algunos casos se generaba por su ausencia o falta de organización.

La investigación realizada permitió establecer el consenso entre las posturas sobre dos aspectos. Primero, el papel destacado de la Fuerza Aérea Colombiana durante la Operación Anorí, mediante el uso de helicópteros Iroquois, equipados para el traslado de tropa, heridos, capturados, muertos, y al comandante del C0-10 Coronel Hernán Hurtado Vallejo. Estas actividades, en concordancia con el apoyo de las otras dos esferas de las Fuerzas Militares y la Policía, permitieron mantener un continuo asedio a las cuadrillas del ELN con el fin de cumplir el objetivo de la misión.

El segundo factor es la trascendencia que tuvo la operación para frenar la expansión organizativa del Ejército de Liberación Nacional, no solo en el territorio antioqueño sino en el país. La muerte de los hermanos Vásquez Castaño, así como las deserciones, capturas y bajas de sus guerrilleros los dejaron reducidos significativamente, tanto así, que la cúpula militar creyó que dicho golpe podría haber sido tan certero que le habían dado fin a esta guerrilla.

Sin embargo, el resurgimiento en los años ochenta del ELN demuestra que no solo por medio de operaciones militares se logra solucionar el conflicto. Además, esta investigación es una invitación ante la imperiosa necesidad que se tiene por conocer e indagar sobre los sucesos desarrollados en el territorio nacional.

\section{REFERENCIAS}

BeHaR, O. (1985). Las guerras de la paz. Bogotá: Planeta.

Bermúdez, G. (1982). El poder militar en Colombia: de la colonia a la contemporaneidad. Bogotá: Ediciones Expresión.

Camargo F., Martínez C., Romero C. y Patiño E. (2017). Fuerzas Militares de Colombia Ejército Nacional II División: el conflicto armado en las regiones. Bogotá: Editorial Universidad del Rosario. 
CARranza, J. (2011). La guerra en los ríos : historia de las unidades fluviales en infantería de marina. Colombia: Asociación colombiana de oficiales de Infantería de Marina, biblioteca Anfibia.

Forero, O. (1994). 75 años en los cielos patrios. Bogotá: Margabby.

Fundación Comité de Solidaridad con los Presos Políticos. (1974). Libro negro de la represión. Frente Nacional 1958-1974. Bogotá: Editorial Gráficas Mundo Nuevo.

Hernández, M. (2004). Rojo y negro. Aproximación a la historia del ELN. Edición digital.

Martínez, G. (2006). Hablan los generales: las grandes batallas del conflicto colombiano contadas por sus protagonistas. Bogotá: Editorial Norma.

MedinA, C. (2001). ELN. Una historia de los orígenes. Bogotá: Rodríguez Quito Editores.

Militares revelan secretos sobre operaciones militares (II). La Operación Anorí. (1975). Alternativa del pueblo, (36), p. 5-8.

Ministerio de Defensa Nacional. (1974). Memoria al Congreso, 1974. Bogotá: Imprenta y publicaciones de las FF-MM.

Ugarriza J. y Pabón, N. (2017). Militares y guerrillas. La memoria histórica del conflicto armado en Colombia desde los archivos militares, 1958-2016. Bogotá: Editorial Universidad del Rosario.

Valencia, A. (1993). Fuerza Aérea Colombiana. Historia de las Fuerzas Militares de Colombia. 5. Bogotá: Planeta.

Villamarín, L. (1999). Cóndor en el Aire-Operación Anorí Conflicto colombiano. Bogotá: Ediciones Luis Alberto Villamarín Pulido.

FUENTES PRENSA

El Colombiano (septiembre y octubre)

El Espectador (septiembre a noviembre)

El Tiempo (agosto a octubre) 


\section{REFERENCIAS PRENSA}

14 soldados perecieron ahogados al zozobrar una embarcación en el río Nechí. (3 de septiembre de 1973). El Colombiano, p.1-21.

Altos mandos van a Anorí. (27 septiembre de 1973). El Espectador, p.1A y $9 \mathrm{~A}$.

Hacia el cementerio. (20 de octubre de 1973). El Colombiano, p. 20.

Los altos mandos en “Operación Anori”.' (28 de septiembre de 1973). El Espectador, p. 5A.

Sepultura secreta a los Vásquez. (20 de octubre de 1973). El Espectador, p.7A.

Un millón de pesos en efectivo. (22 de septiembre de 1973). El Colombiano, p. 7.

Velásquez, Javier. (20 de octubre de 1973). Por errores tácticos cayeron los Vásquez Castaño. El Colombiano, p. 20. 